\title{
Pythium species from rice roots differ in virulence, host colonization and nutritional profile
}

\author{
Evelien Van Buyten and Monica Höfte*
}

\begin{abstract}
Background: Progressive yield decline in Philippine aerobic rice fields has been recently associated with three closely related Pythium spp., $P$. arrhenomanes, $P$. graminicola and $P$. inflatum. To understand their differential virulence towards rice seedlings, we conducted a comparative survey in which three isolates each of $P$. arrhenomanes, $P$. graminicola and $P$. inflatum were selected to investigate host colonization, host responses and carbon utilization profiles using histopathological analyses, phenoarrays, DNA quantifications and gene expression studies.
\end{abstract}

Results: The isolate of the most virulent species, $P$. arrhenomanes, quickly colonized the outer and inner root tissues of rice seedlings, including the xylem, by which it possibly blocked the water transport and induced severe stunting, wilting and seedling death. The lower virulence of the tested $P$. graminicola and $P$. inflatum isolates seemed to be reflected in slower colonization processes, limited invasion of the vascular stele and less systemic spread, in which cell wall fortification appeared to play a role. Progressive hyphal invasions triggered the production of reactive oxygen species (ROS) and phenolic compounds, which was the strongest for the $P$. arrhenomanes isolate and was delayed or much weaker upon inoculation with the $P$. inflatum isolate. The necrosis marker OsJamyb seemed faster and stronger induced by the most virulent isolates. Although the isolate of $P$. inflatum was nutritionally the most versatile, the most virulent Pythium isolate appeared physiologically more adapted to its host, evidenced by its broad amino acid utilization profile, including D-amino acids, L-threonine and hydroxyl-L-proline. The latter two compounds have been implicated in plant defense and their use by P. arrhenomanes could therefore represent a part of its virulence strategy.

Conclusions: This study illustrates that the differential virulence of rice-pathogenic $P$. arrhenomanes, $P$. graminicola and $P$. inflatum isolates is related to their root colonization capacity, the intensity of induced root responses and their ability to utilize amino acids in their colonization niche. Accordingly, this paper presents important knowledge concerning rice root infections by oomycetes, which could be helpful to further disentangle virulence tactics of soil-borne pathogens.

Keywords: Pythium, Oryza sativa L, Root-oomycete interaction, Histopathology, Jasmonic acid (JA), Phenoarray, Amino acids

\section{Background}

Pythium species are ubiquitous soil-borne oomycetes that rank from opportunistic up to highly virulent pathogens on many plant species. They mainly infect young plant tissues and cause pre- and post-emergence damping off or reduce the vigor and growth of surviving seedlings. Besides, they infect mature plant roots, resulting in severe

\footnotetext{
* Correspondence: monica.hofte@ugent.be

Laboratory of Phytopathology, Department of Crop Protection, Faculty of Bioscience Engineering, Ghent University, Coupure Links 653, B-9000 Ghent, Belgium
}

\section{Biomed Central}

necrosis and stunting [1]. Several important graminaceous crops, including maize, wheat, rice, sugarcane, barley, sorghum and turf grasses have been mentioned to suffer from Pythium attacks [2]. Recently, P. arrhenomanes, $P$. graminicola and P. inflatum were associated with progressive yield decline in Philippine aerobic rice fields [3]. These closely related Pythium spp. exhibited a varying degree of virulence towards aerobic rice seedlings, among which $P$. arrhenomanes was the most virulent and inflicted a strong pre- and post-emergence damping-off, 
and stunting of rice shoots, while $P$. graminicola was less virulent and $P$. inflatum is nonpathogenic in vivo.

Few histopathological studies have monitored the infection process of Pythium spp. in monocot roots. We lately surveyed the interaction of $P$. graminicola with rice seedling roots [4] and revealed that this pathogen quickly invaded the rice rhizodermis via penetration hyphae, after which it generated a dense intracellular network in the inner root tissues and ultimately triggered necrosis. Modjehi et al. (1991) [5] investigated the infection of wheat roots by $P$. arrhenomanes and in this study, the oomycete appeared to penetrate wheat roots via appressoria-like structures. This pathogen also intracellularly invaded the root cortex and, to a lesser extent, the stele, which eventually resulted in severe cortical cell collapse and strong browning of wheat roots. In addition, the interaction between $P$. arrhenomanes and corn has been analyzed [6], and demonstrated that P. arrhenomanes developed two different types of hyphae during its colonization of corn roots. To our knowledge, studies on the interaction of rice roots with $P$. arrhenomanes or $P$. inflatum are currently lacking. Furthermore, comparative histopathological analyses with highly and weakly virulent Pythium spp. on monocot roots have never been executed.

Therefore, we explored the rice root colonization processes of one isolate each of $P$. arrhenomanes, $P$. graminicola and $P$. inflatum from diseased aerobic rice fields in the Philippines. In vitro infection trials allowed the accurate evaluation of rice root and shoot development upon Pythium inoculation, and histological and molecular techniques were used to unravel qualitative and quantitative differences among the infection processes of these three Pythium isolates. Using similar techniques, rice root responses to Pythium were investigated over time. In addition, phenoarrays were carried out to reveal the nutritional needs of the three oomycetes and to identify carbonutilization patterns related to a higher virulence. Our research discovered clear differences in the root colonization capacity and nutritional profiles of rice-infecting $P$. arrhenomanes, P. graminicola and P. inflatum isolates.

\section{Results}

\section{Macroscopic symptoms on rice seedlings upon Pythium} infection

Rice seedlings (cv. Nipponbare) were cultured on Gamborg B5 (GB5) agar plates to study the effect of $P$. arrhenomanes PT 60, P. graminicola PB912 132 and P. inflatum PT 52 on root and shoot development. Macroscopic evaluation of Pythium-inoculated rice seedlings illustrated the intense colonization of rice tissues by the $P$. arrhenomanes isolate (Figure 1). Both rice seed and root surfaces became massively covered with aerial mycelium by 2 days post inoculation (dpi). When the infection proceeded, the mycelium concentrated primarily on and in the vicinity of the rice seeds. Similarly, a dense white mycelium appeared on the seeds of P. inflatum PT 52-inoculated cultures by 2 dpi. The superficial colonization was, however, less pronounced in this case. Hyphae of P. graminicola PB912 132 grew well in the medium adjacent to the rice seeds, but rice seedling surfaces were never heavily colonized. When nutrients were eliminated from the medium, we still observed a stimulated hyphal growth near the rice seeds (data not shown). This growth stimulation was probably due to seed exudation. When the Pythium isolates were cultured in seed exudates alone, an increased hyphal growth was indeed observed (Additional file 1: Figure S1).

Evaluation of the in vitro cultures at $10 \mathrm{dpi}$ revealed that rice seedlings were very susceptible to $P$. arrhenomanes PT 60 and P. graminicola PB912 132 infection (Figure 1, Table 1). The most virulent isolate $P$. arrhenomanes PT 60 inhibited crown root and lateral root formation. Besides, primary root lengths were significantly reduced by $63 \%$ compared to the non-inoculated control $(P \leq 0.05)$. Necrosis was visible as typical brown discolorations on the upper part of the primary roots. When shoot growth was

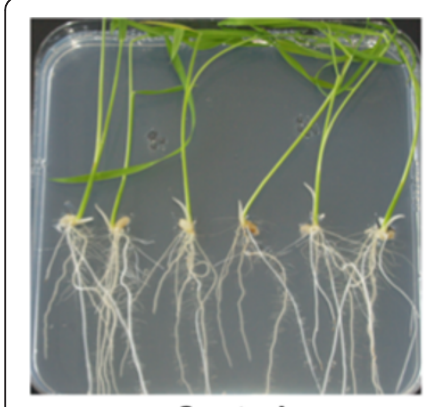

Control

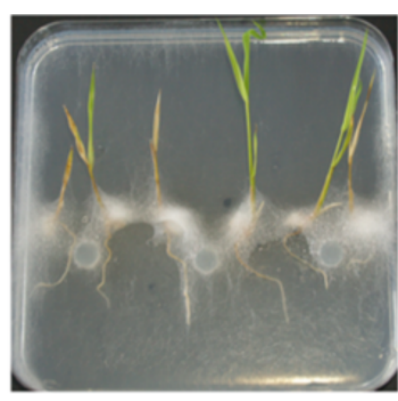

$P$. arrhenomanes

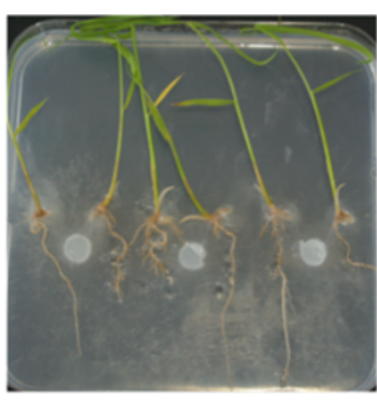

P. graminicola

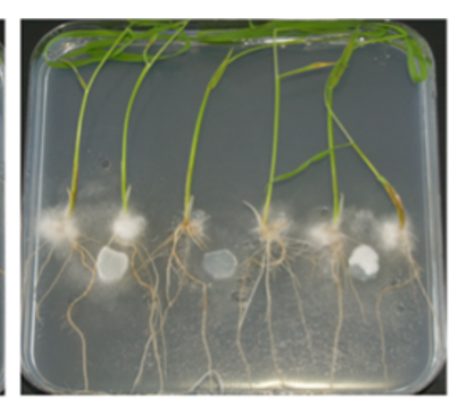

P. inflatum

Figure 1 Disease symptoms on rice seedlings 10 days after Pythium inoculation. Clear differences in stunting and wilting were noticed among $P$. arrhenomanes-, P. graminicola- and P. inflatum-inoculated rice seedlings. Rice seeds were germinated on Gamborg B5 medium and three days post imbibition, seedlings were inoculated with mycelial plugs. Three replicate plates were evaluated per treatment. Pictures are representative for all replicates. 
Table 1 Pythium-induced disease symptoms on rice seedlings at $10 \mathrm{dpi}$

\begin{tabular}{|c|c|c|c|c|}
\hline Species & Shoot length $(\mathrm{cm})^{*}$ & Root length $(\mathrm{cm})^{*}$ & DSI\% ${ }^{* *}$ & Dead seedlings $\%^{* * *}$ \\
\hline Control & $16.07(0.34) \mathbf{a}$ & $9.19(0.43) \mathbf{a}$ & $3(1.92) \mathbf{a}$ & $0 \mathrm{a}$ \\
\hline P. arrhenomanes & $6.24(0.62) \mathbf{b}$ & $3.42(0.15) \mathbf{b}$ & $59(7.22) \mathbf{b}$ & $28(11.11) \mathbf{b}$ \\
\hline P. graminicola & $10.26(0.57) \mathbf{c}$ & $4.74(0.23) \mathbf{c}$ & $32(1.00) \mathbf{c}$ & $0 \mathbf{a}$ \\
\hline P. inflatum & $17.97(0.42) \mathbf{a}$ & $9.06(0.50) \mathbf{a}$ & $23(0) \mathbf{d}$ & $0 \mathbf{a}$ \\
\hline
\end{tabular}

${ }^{*}$ Mean shoot and root length data $(\mathrm{n}=18)$.

${ }^{* *}$ Average disease severity indices (DSI) $(n=3)$ were calculated using the disease severity scale (see "Methods"). Indices vary from $0 \%$ (healthy shoots) up to $100 \%$ (dead shoots) and illustrate the degree of yellowing or browning in culms and leaves in parallel with shoot stunting. Eighteen plantlets were individually scored for each treatment.

${ }^{* * *}$ The percentage of dead seedlings displays the mean number of shoots $(n=3)$ with disease severity score 5 .

Statistical analyses were mostly performed by Kruskal-Wallis and Mann-Whitney non-parametric tests in SPSS 21 (SPSS Inc.). Only shoot length data were normally distributed and therefore, analyzed with one-way ANOVA and the Duncan Post-Hoc test. In each column, distinct lower case letters (a,b,c,d) indicate significant differences between the treatments $(a=0.05, P \leq a)$. Values between brackets are standard errors.

monitored, a significant stunting of $61 \%$ relative to the control became evident $(P \leq 0.05)$. Furthermore, $72 \%$ of all inoculated rice seedlings exhibited clear wilting symptoms, visible as yellowing or browning of culms and/or leaves. The high virulence level of $P$. arrhenomanes PT 60 also resulted in a significant seedling death of $28 \%(P \leq 0.05)$, i.e. the percentage of plantlets with shoot disease severity score 5.

In contrast to the $P$. arrhenomanes isolate, $P$. graminicola PB912 132 never impaired crown root and lateral root formation in rice seedlings. Nonetheless, all root types were highly stunted and exhibited an overall clear brown discoloration. Primary root lengths were significantly shorter $(P \leq 0.05)$, with lengths representing $52 \%$ of those of the non-inoculated control. Opposing the strong wilting symptoms on $P$. arrhenomanes PT 60-inoculated rice seedlings, shoots appeared significantly healthier $(P \leq 0.05)$ and survived all upon P. graminicola PB912 132 inoculation. Moreover, shoot growth was reduced by $36 \%$, which was significantly less $(P \leq 0.05)$ than the stunting evoked by the most virulent isolate. The impact of $P$. inflatum PT 52 on rice seedling development was rather minor in comparison with the isolates of the other species (Figure 1, Table 1). Except for a curtailed crown root elongation and necrotic patches on primary, crown and lateral roots, no apparent disease symptoms were observed. Maximal root lengths of $P$. inflatum PT 52-inoculated seedlings represented $99 \%$ of the control treatment. In addition, shoot stunting was only $7 \%$ and appeared not significant $(P>0.05)$. Most shoots were categorized in the lowest disease score, exhibiting only few symptoms of wilting. Disease severity indices were still significantly distinct from the control treatment $(P \leq 0.05)$ indicating that $P$. inflatum is weakly virulent in vitro.

\section{Histological study of the Pythium infection process in rice roots}

To investigate the colonization process of $P$. arrhenomanes PT 60, P. graminicola PB912 132 and P. inflatum PT 52 inside rice roots, we examined trypan blue-stained root cuttings with bright field microscopy. The three Pythium isolates invaded primary roots via direct penetration of epidermal cells (Figure 2A). Swollen hyphae rather than specialized appressoria were used as penetration tools. Immediately after Pythium ingress, hyphae differentiated in irregularly inflated structures that headed intracellularly to the walls of neighboring cells. Right before cell wall crossing, hyphae became dramatically constricted (Figure 2A). The same strategy was likely adopted during the further spread of Pythium hyphae in the cortex and vascular tissue.

However, the isolates of $P$. arrhenomanes, $P$. graminicola and $P$. inflatum differed in the extent to which inner root tissues were colonized. In the most heavily infected parts of the primary root (the upper $1.5 \mathrm{~cm}$ ), the three Pythium isolates strongly colonized the cortex, endodermis and stele within 27 hpi (Figure 2B). A more detailed view onto the stele unraveled the numerous hyphae that were present in the phloem and xylem by that time (Figure 2C). Histological studies on the middle part of the primary root generated similar results for the $P$. arrhenomanes PT 60 colonization process, while P. graminicola PB912 132 hyphae were less abundant in the cortex and vascular tissue (Figure 2D). Besides, the latter pathogen did not invade xylem cells in the majority of the examined cross-sections. In P. inflatum PT 52-inoculated root samples, the occurrence of a dense hyphal network was less frequent compared to P. arrhenomanes PT 60 and P. graminicola PB912 132-inoculated root samples. In addition, the colonization of the root stele was often limited to the outer cell layers.

\section{Quantification of Pythium DNA in rice roots}

It has been stated that the combination of qualitative and quantitative techniques allows more accurate time-course monitoring of microbial infection processes in plant roots [7]. Therefore, a DNA-based quantification method was used to further survey the colonization of rice seedling roots by $P$. arrhenomanes PT 60, P. graminicola PB912 132 and P. inflatum PT 52. Quantitative Real-Time PCR 


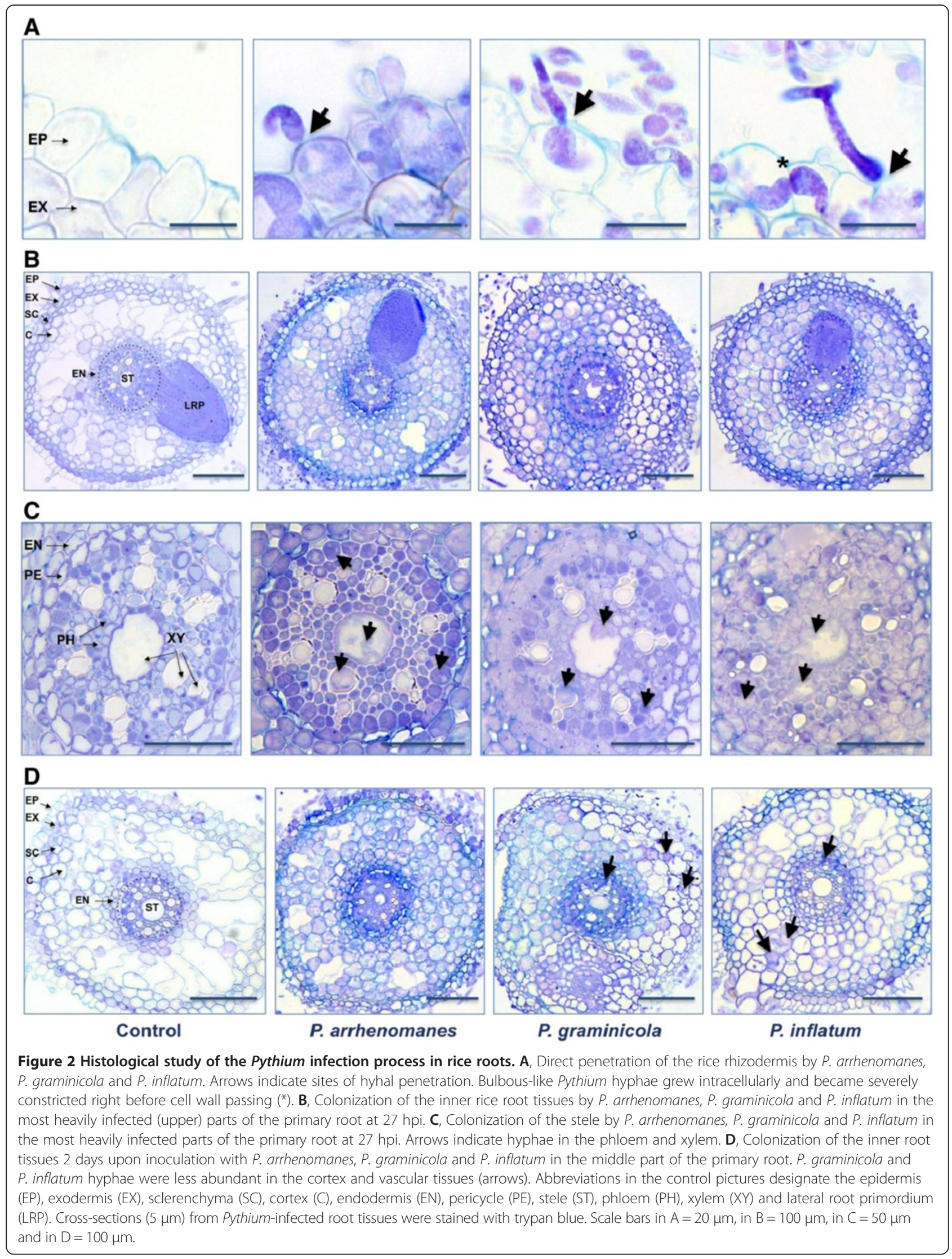


(qPCR) on non-surface-sterilized root samples illustrated that $P$. arrhenomanes PT 60 quickly and massively colonized the entire rice root system (Table 2A). In a first experiment (Exp 1), DNA quantities of the tested P. arrhenomanes isolate represented $8.42 \%$ of the total DNA extract at $1 \mathrm{dpi}$, which strongly increased up to $49.2 \%$ and $59 \%$ by 2 and $3 \mathrm{dpi}$, respectively. Quantities of P. graminicola PB912 132 DNA were much lower and maintained more or less the same level over time (i.e. 5-6\%). The concentration of P. inflatum PT $52 \mathrm{DNA}$ on and in rice seedlings roots elevated from $1.39 \%$ at $1 \mathrm{dpi}$ up to $26.4 \%$ at $2 \mathrm{dpi}$, after which it diminished down to $15.8 \%$ by $3 \mathrm{dpi}$.

A second experiment (Exp 2) generated similar increasing trends for the colonization process of the $P$. arrhenomanes isolate. In P. graminicola PB912 132- and $P$. inflatum PT 52-inoculated roots, consistent DNA concentrations were measured at 3 dpi (i.e. 5\% and $19.6 \%$, respectively), but during the first days, the quantities were respectively higher and lower compared to the first experiment.

qPCR on surface-sterilized root samples enabled the quantification of Pythium DNA inside the rice root system. Once more, the concentration of $P$. arrhenomanes PT 60 DNA clearly elevated over time (Table 2B), with quantities of $0.13 \%$ at $20 \mathrm{hpi}$ that multiplied up to $0.84 \%$ at $28 \mathrm{hpi}$ and $4.77 \%$ at $73 \mathrm{hpi}(\operatorname{Exp} 1)$. In contrast, the concentration of P. graminicola PB912 132 DNA inside the rice seedling root system was much lower at 20 hpi. Nonetheless, by 73 hpi, DNA quantities of the $P$. arrhenomanes and $P$. graminicola isolates attained equal amounts. The share of $P$. inflatum PT 52 DNA in the total DNA extract was very low during the first $20 \mathrm{~h}$ of the infection process. From 28 hpi on, DNA quantities slightly elevated up to approximately $0.1 \%$, but remained much lower than those of the other species. Despite the overall lower infection level in our second experiment, we could observe similar colonization trends for the three Pythium isolates. Taken together, these data imply that the tested $P$. arrhenomanes isolate is a better and faster colonizer of rice root surfaces and inner tissues than the screened $P$. graminicola and $P$. inflatum isolates. Furthermore, they demonstrate that the isolate of the weakly virulent species $P$. inflatum mainly colonizes rice root surfaces, while the isolate of P. graminicola is less efficient in its superficial spread.

\section{Rice root responses to Pythium spp \\ Reactive oxygen species (ROS)}

The accumulation of hydrogen peroxide $\left(\mathrm{H}_{2} \mathrm{O}_{2}\right)$ in Pythium-inoculated rice seedling roots was visualized with bright field microscopy and an endogenous peroxidasedependent staining procedure using 3,3'-diaminobenzidine (DAB).

When the most heavily infested (upper) parts of the primary roots were analyzed, we detected reddish-brown DAB precipitates in the outer cell layers (Figure 3, black arrows). At $1 \mathrm{dpi}, \mathrm{H}_{2} \mathrm{O}_{2}$ production appeared the strongest in $P$. arrhenomanes PT 60-inoculated seedling roots, where they accumulated in the sclerenchyma and some cortical cells. By $2 \mathrm{dpi}$, these DAB precipitates became less visible. In P. graminicola PB912 132-inoculated seedlings, $\mathrm{DAB}$ concentrated in the epidermis and exodermis of the roots, and this $\mathrm{H}_{2} \mathrm{O}_{2}$ production also diminished by $2 \mathrm{dpi}$. On the contrary, DAB precipitates were barely noticeable during the first $24 \mathrm{~h}$ of the $P$. inflatum PT 52-rice interaction. By $2 \mathrm{dpi}$, the $\mathrm{H}_{2} \mathrm{O}_{2}$ production slightly increased in the epidermis, exodermis and sclerenchyma of seedling roots, but overall rice roots seemed to respond less upon inoculation with this isolate. DAB accumulation did not occur in control roots, with the exception of the vascular tissue and aerenchym.

When the middle part of the primary root was examined, we also observed DAB accumulation in the outer

Table 2 In planta quantification of Pythium DNA (pg/ng total DNA) using qPCR

\begin{tabular}{|c|c|c|c|c|c|c|}
\hline & \multicolumn{2}{|c|}{ P. arrhenomanes* } & \multicolumn{2}{|c|}{ P. graminicola* } & \multicolumn{2}{|c|}{ P. inflatum* } \\
\hline & $\operatorname{Exp} 1$ & $\operatorname{Exp} 2$ & $\operatorname{Exp} 1$ & $\operatorname{Exp} 2$ & $\operatorname{Exp} 1$ & $\operatorname{Exp} 2$ \\
\hline \multicolumn{7}{|l|}{$\bar{A}$} \\
\hline $1 \mathrm{dpi}$ & $84.24(0.40)$ & $179.26(17.85)$ & $57.76(4.70)$ & 179.64 (8.94) & $13.88(0.64)$ & $2.89(0.27)$ \\
\hline $2 \mathrm{dpi}$ & $492.00(28.28)$ & $291.42(19.37)$ & $47.28(0.85)$ & $142.00(30.60)$ & $264.10(03.65)$ & $113.44(2.09)$ \\
\hline $3 \mathrm{dpi}$ & $590.00(36.77)$ & 405.32 (82.99) & $58.40(1.58)$ & $51.14(10.78)$ & $157.70(25.37)$ & $196.16(6.79)$ \\
\hline \multicolumn{7}{|l|}{ B } \\
\hline $20 \mathrm{hpi}$ & $1.246(0.141)$ & $2.162(2.437)$ & $0.330(0.027)$ & $0.031(0.001)$ & $0.010(0.006)$ & $0.003(0.001)$ \\
\hline $28 \mathrm{hpi}$ & $8.434(0.240)$ & $8.782(0.167)$ & $8.958(0.325)$ & $1.128(0.082)$ & $0.966(0.040)$ & $0.108(0.006)$ \\
\hline $73 \mathrm{hpi}$ & $47.680(4.299)$ & $4.564(0.238)$ & $55.320(6.505)$ & $0.332(0.040)$ & $0.857(0.157)$ & $0.019(0.001)$ \\
\hline
\end{tabular}

*In each experiment (Exp 1 and 2) 12 rice seedlings were pooled per treatment at various times. The presented data are means of two technical replicates ( $\mathrm{n}=2$ ). Values between brackets represent standard deviations.

A, Concentration of Pythium DNA in non-surface sterilized rice seedlings roots. Seeds were germinated on Gamborg B5 medium and inoculated at three days post imbibition. Root samples were collected in two different experiments at various times upon inoculation. B, Concentration of Pythium DNA in surface sterilized rice seedling roots. Seeds were germinated on plant agar-medium and inoculated at three days post imbibition. Rice roots were collected in two different experiments at various times upon inoculation and were surface-sterilized prior to processing. 


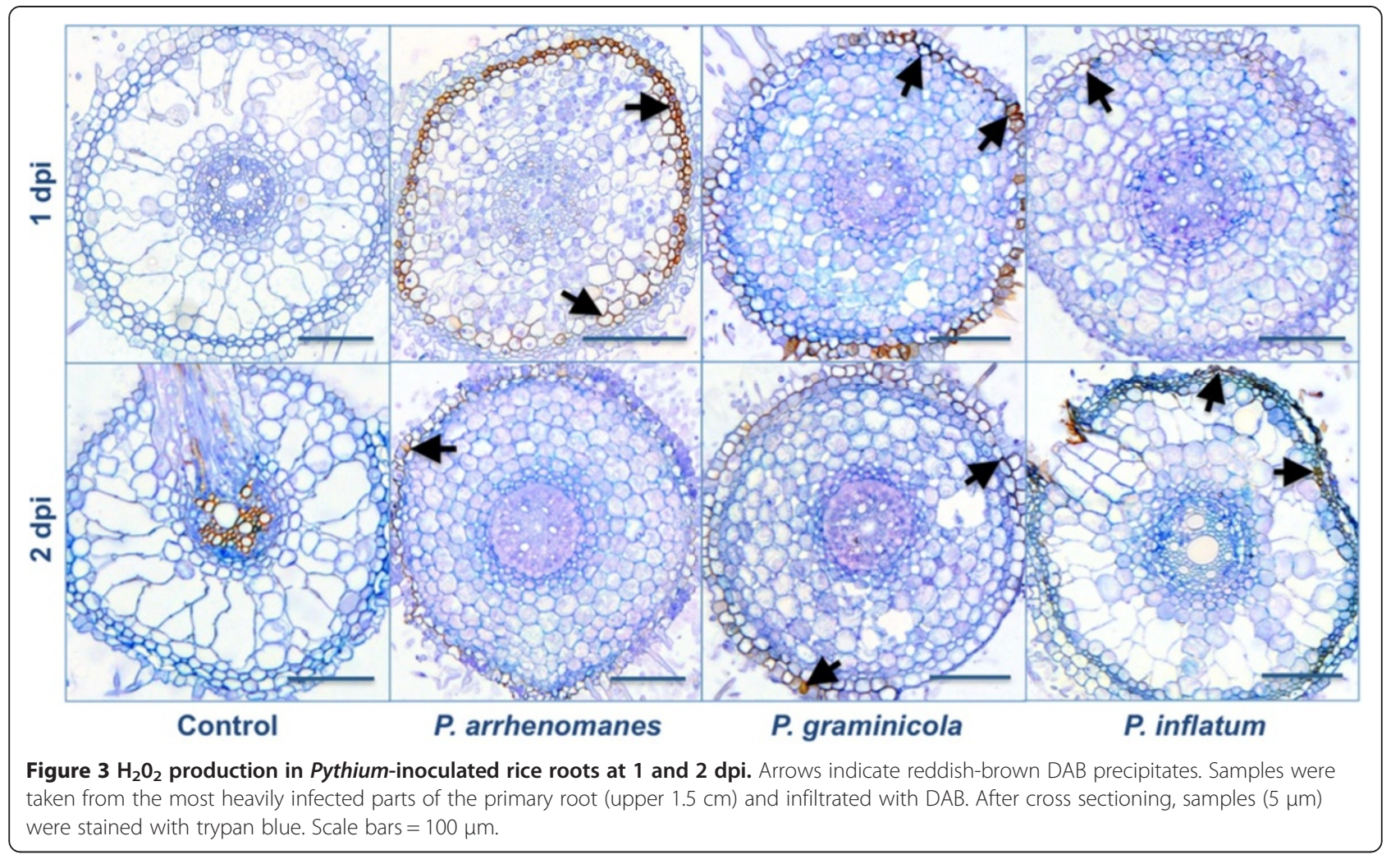

and inner cortex of P. inflatum PT 52- and P. graminicola PB912 132-inoculated seedlings at 3 dpi (Figure 4, black arrows). In both cases, hyphal proliferation in a part of the root cortex was hampered and colonization was slowed down. In P. arrhenomanes PT 60-inoculated seedlings, cortical cells seemed to collapse at this stage of the infection (Figure 4, blue arrows).

\section{Phenolic compounds}

The accumulation of phenolic compounds in Pythiuminoculated rice seedling roots was visualized as an orange- brown autofluorescence by UV-excitation of calcofluor white M2R-stained root cuttings.

The autofluorescence was visible from 2 dpi on (Figure 5, white arrows) and was the strongest in $P$. arrhenomanes PT 60-inoculated rice seedling roots, where it was emitted from parts of the outer root cortex and the sclerenchyma. In P. graminicola PB912 132-inoculated root cuttings, phenolic compounds were primarily visible in the sclerenchyma and little autofluorescence was emitted from the vascular tissue. Similarly, we detected autofluorescence in the sclerenchyma of $P$. inflatum PT 52-inoculated rice roots, but once more, the host responded the weakest to

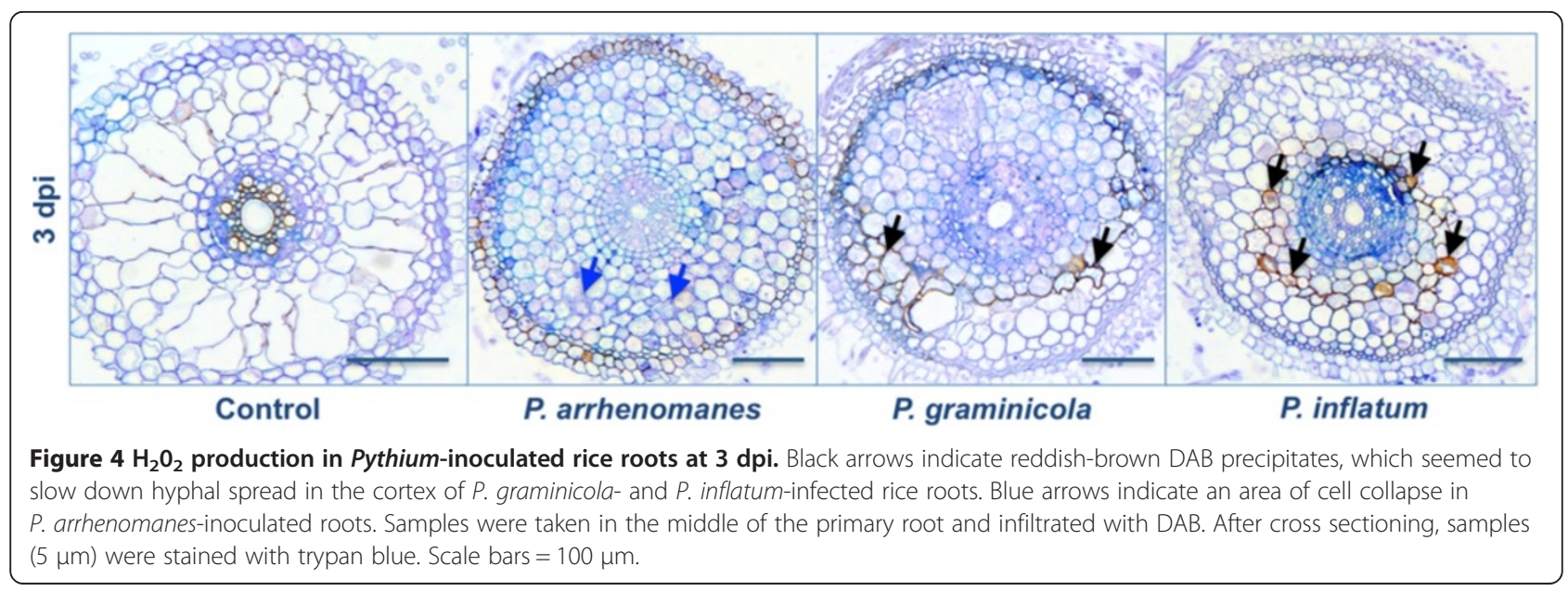




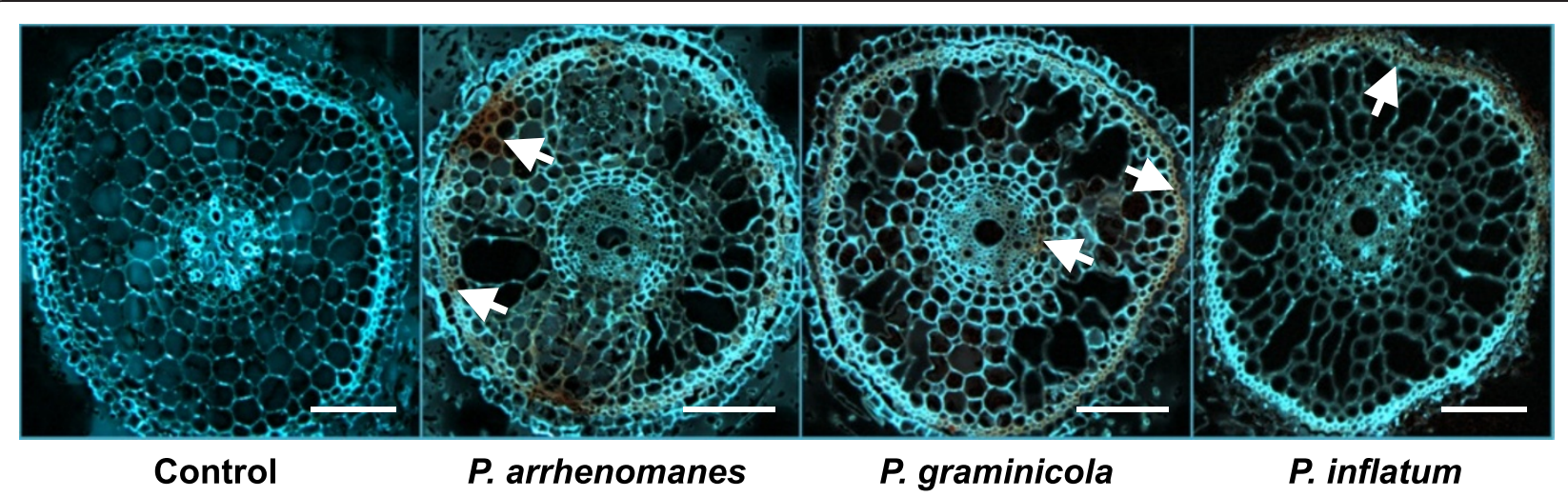

Figure 5 Accumulation of phenolic compounds in Pythium-inoculated rice roots at $\mathbf{2} \mathbf{d p i}$. White arrows indicate the orange-colored autofluorescence upon Pythium infection. Cross-sections $(5 \mu \mathrm{m})$ from Pythium-infected root tissues were stained with Calcofluor white M2R and excited with UV. Scale bars $=100 \mu \mathrm{m}$.

this isolate. No autofluorescence was detected in control roots.

\section{Expression of the necrosis marker and JA-responsive gene OsJAmyb}

To compare the degree of induced necrosis among P. arrhenomanes PT 60-, P. graminicola PB912 132- and $P$. inflatum PT 52-inoculated root systems, the expression of OsJAmyb was analyzed by $\mathrm{qPCR}$ analysis. This JA- and pathogen-inducible MYB transcription factor has been identified as a necrosis marker and is mainly expressed in plant tissues prior to cell death [8]. Our gene expression analysis revealed that the three Pythium isolates induced necrosis in rice seedling roots (Figure 6). P. arrhenomanes PT 60 showed to strongly trigger necrosis at 1,3 and $4 \mathrm{dpi}$, when a respective 21.3 -fold, 16fold and 13.4-fold induction in OsJAmyb transcription was measured. By $6 \mathrm{dpi}$, the transcription decreased down to 5.3-fold and approximated the expression level in the control. In P. graminicola PB912 132-inoculated root tissues we noted a lower induction of OsJAmyb during the first days of the infection. By $6 \mathrm{dpi}$, the expression of the necrosis marker strongly elevated up to 16.2-fold and seemed to exceed the level in $P$. arrhenomanes PT 60inoculated roots. Necrosis was barely triggered during the first days upon inoculation with the P. inflatum isolate. Only at $6 \mathrm{dpi}$, mRNA levels strongly elevated (9.4-fold).

\section{Isolates of P. arrhenomanes and P. graminicola are} nutritionally less versatile than that of $P$. inflatum

The growth of one isolate each of $P$. arrhenomanes, $P$. graminicola and $P$. inflatum on various carbon sources was evaluated using phenoarrays. This analysis revealed the ability of $P$. inflatum isolate PT 52 to use a broad range of carbohydrates, amino acids, carboxylic acids and derivatives (Figure 7 and 8 ).

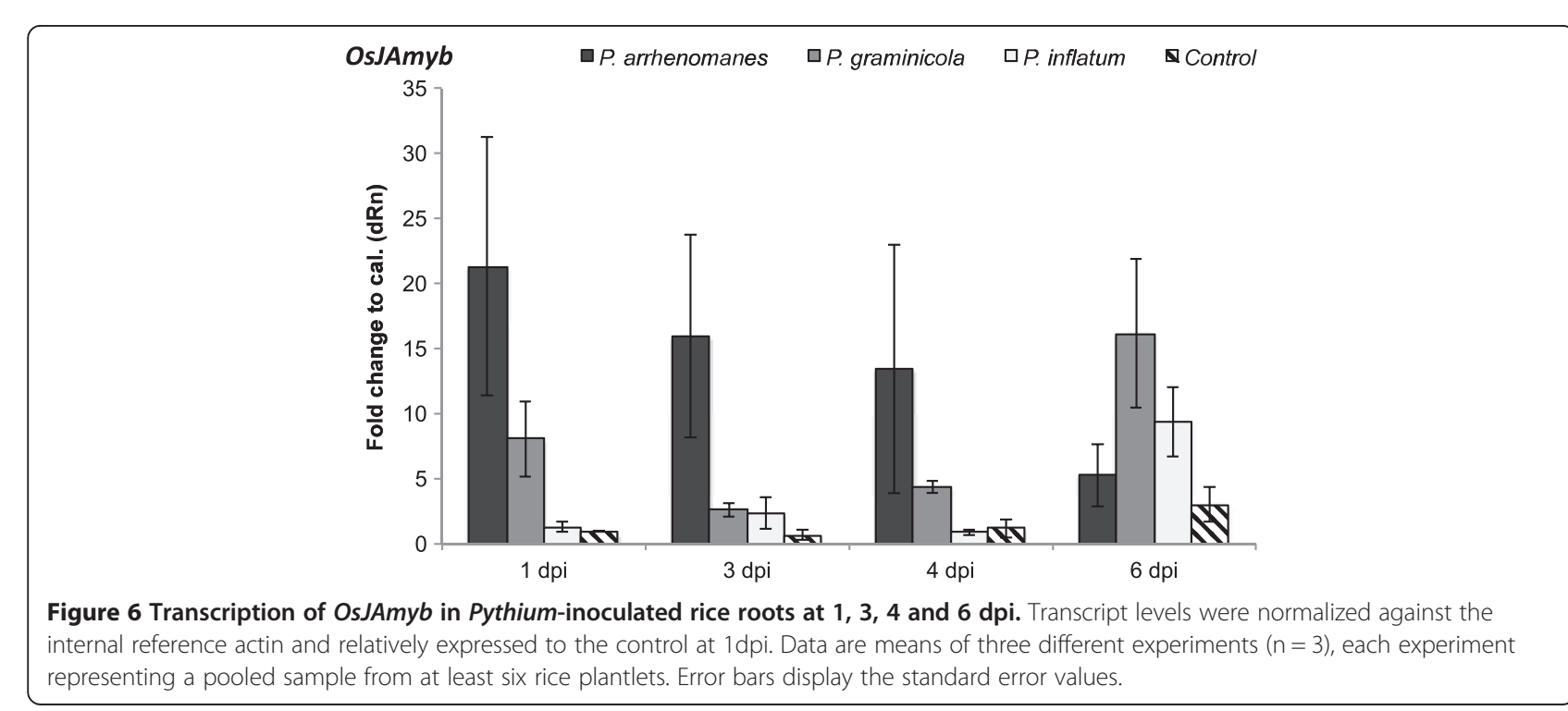


The P. inflatum isolate used $80 \%$ of all mono-, di-, triand polysaccharides, sugar monomers/polymers, glycosides and polyols supplemented to the MicroPlates, while this was only $49 \%$ and $47 \%$ for P. arrhenomanes PT 60 and P. graminicola PB912 132, respectively (Figure 7; Additional file 2: Table S1, Additional file 3: Table S2). The latter isolates did not metabolize glycosides of galactose and mannose, while all glycosides stimulated the growth of $P$. inflatum PT 52. Furthermore, only 56\% and $44 \%$ of the tested polyols were utilized by $P$. arrhenomanes PT 60 and P. graminicola PB912 132, respectively, whereas this was $89 \%$ in the case of P. inflatum PT 52 . It was interesting to see that the tested isolates of $P$. arrhenomanes and $P$. graminicola grew on different polyols beside glycerol and $\mathrm{m}$-inositol. Compared to the $P$. inflatum isolate, they were also less efficient in their use of several saccharides, in particularly monosaccharides. Nevertheless, the overall highest absorbance values $(\mathrm{OD}>0.35)$ were measured in wells pre-filled with the disaccharides sucrose, maltose, gentiobiose and D-cellobiose, and the monosaccharide $\alpha$-D-glucose. Turbidities in wells inoculated with $P$. inflatum PT52 were the highest for these compounds, supporting its better growth on carbohydrates compared to the other species. Besides, the $P$. graminicola and $P$. arrhenomanes isolates grew the best on D-fructose (monosaccharide) and D-trehalose (disaccharide), and glycogen (polysaccharide), respectively. P. arrhenomanes PT 60 and P. inflatum PT 52 shared the ability to use D-galactose, while the isolates of $P$. inflatum and $P$. graminicola, but not $P$. arrhenomanes, were able to use lactulose.

When exploring the growth of the three Pythium isolates on amino acids, carboxylic acids and their derivatives, it became clear that $P$. inflatum PT 52 and $P$. arrhenomanes PT 60 could use respectively $68 \%$ and $61 \%$ of these compounds, while this was only $43 \%$ for
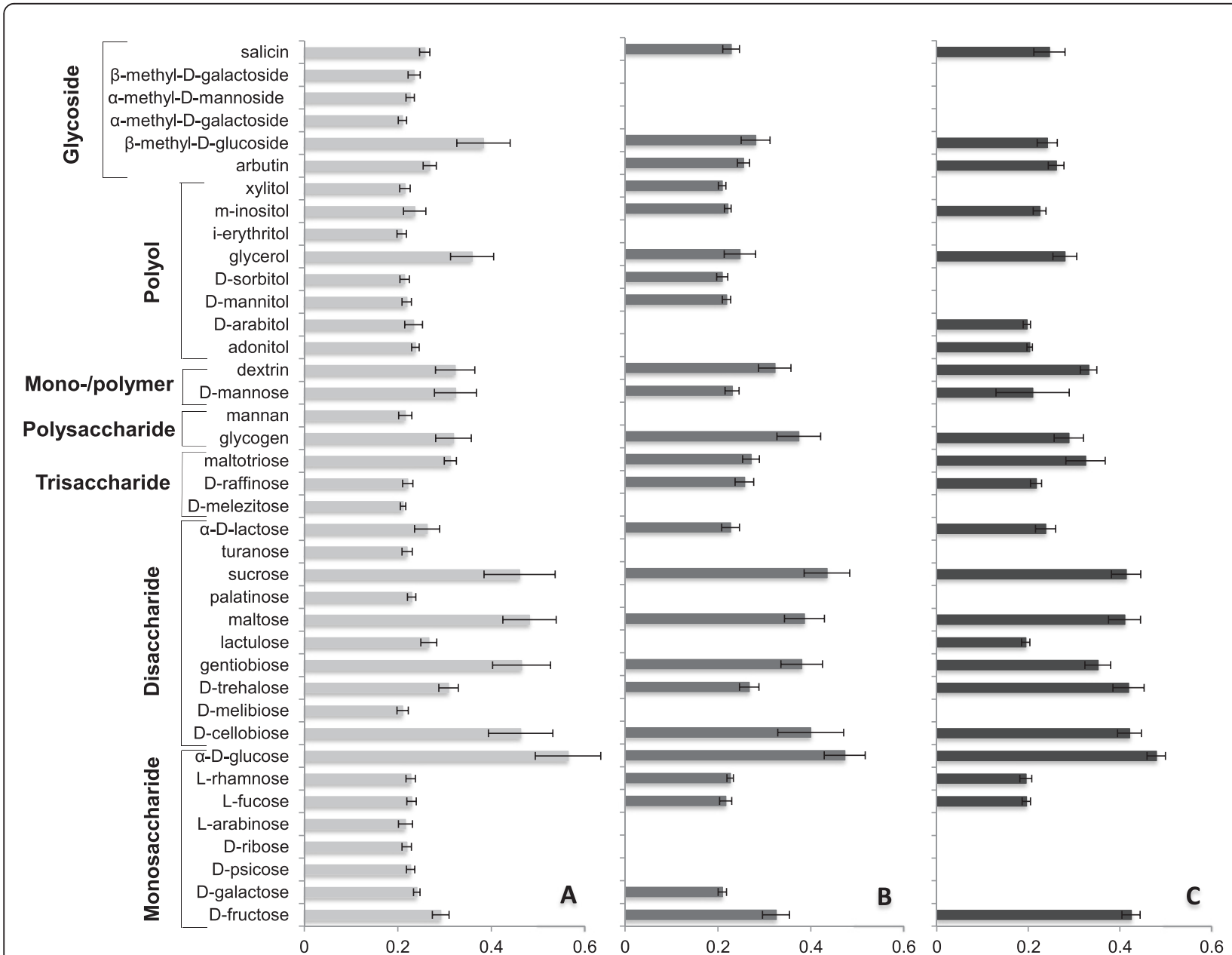

Figure 7 Carbohydrates and derivatives metabolized during in vitro growth of rice-infecting Pythium spp. A, B and C represent the profiles of $P$. inflatum, P. arrhenomanes and P. graminicola, respectively. Turbidimetrical measurements were executed 24 hpi. The experiment consisted of three replicate plates per treatment and was repeated in time $(n \geq 6)$. Only carbon sources with OD-values significantly different from the control-treatment are presented. Statistical analyses were performed using the Kruskal-Wallis non-parametric test in SPSS $21(\alpha=0.05, P \leq a)$. 


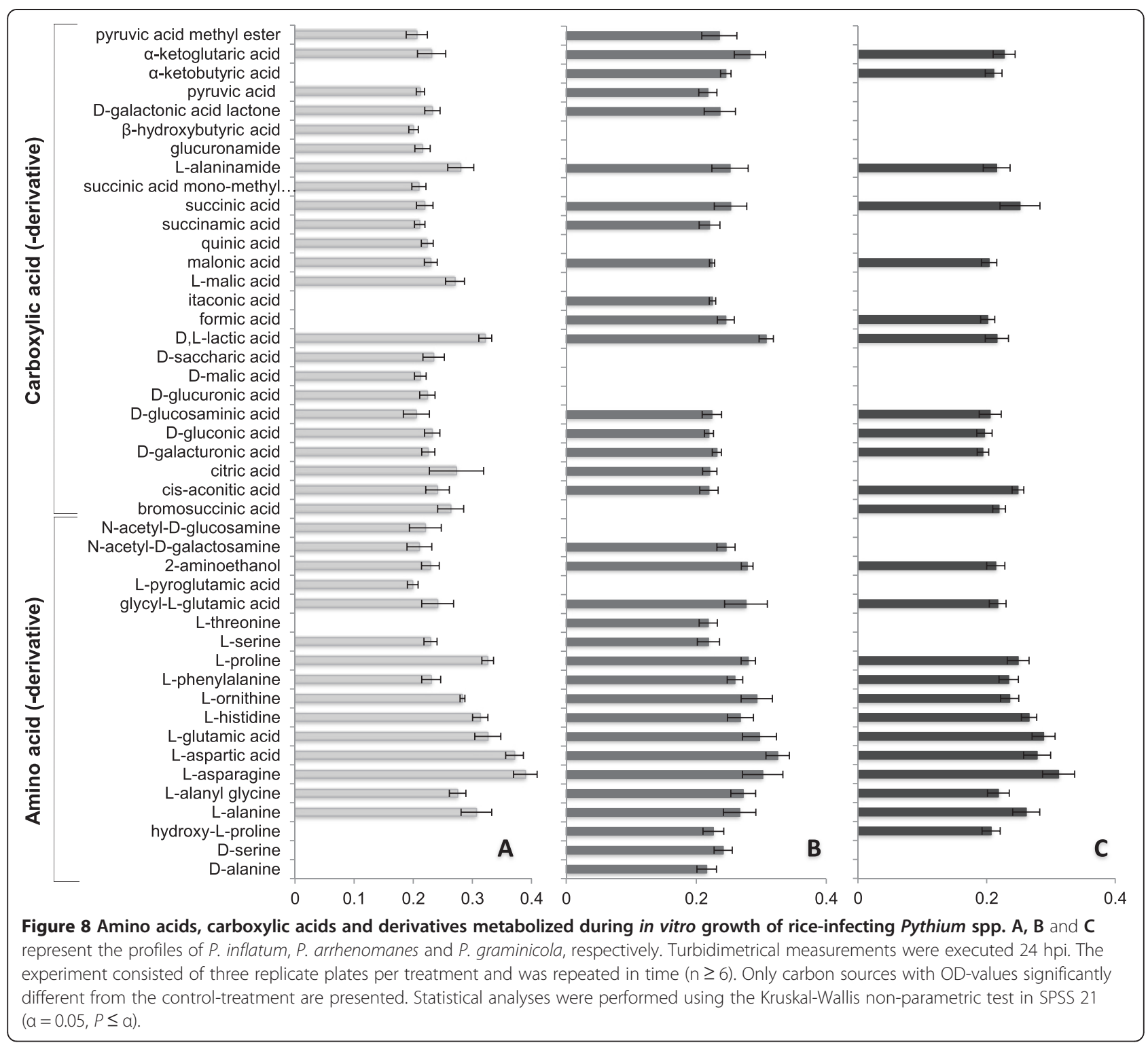

P. graminicola PB912 132 (Figure 8; Additional file 2: Table S1, Additional file 3: Table S2). The screened isolate of $P$. inflatum exhibited the broadest carboxylic acidprofile and was the only isolate that could utilize quinic acid, D,L-malic acid, D-saccharic acid, D-glucuronic acid and $\beta$-hydroxybutyric acid. Nevertheless, it was not able to metabolize two particular carboxylic acids, i.e. formic acid and $\alpha$-ketobutyric acid, which intriguingly showed to stimulate the growth of the more virulent isolates. Aside from these findings, P. arrhenomanes PT 60 appeared unique in its ability to use itaconic acid, while no carboxylic acids or derivatives seemed specific for $P$. graminicola PB912 132 (Table 3). We also identified certain carboxylic acids that enhanced the growth of either the $P$. arrhenomanes and $P$. inflatum isolates or the P. graminicola and P. inflatum isolates (Table 3).
The amino acid-profiles of all tested Pythium isolates included L-alanine, L-alanyl-glycine, L-asparagine, L-aspartic acid, L-glutamic acid, L-histidine, L-ornithine, L-phenylalanine and L-proline. However, L-threonine, D-serine and D-alanine were exclusively used by $P$. arrhenomanes PT60 and hence, it exhibited the broadest amino acid profile among the three Pythium isolates (Figure 8). P. inflatum PT 52 and P. arrhenomanes PT 60 could both utilize L-serine, while P. graminicola PB912 132 could not. Interestingly, the use of hydroxy-L-proline seemed specific for the more virulent Pythium isolates and none of the three isolates showed growth on L-leucine (Additional file 3: Table S2).

The three Pythium isolates also responded differently to certain other carbon sources (Additional file 2: Table S1). The nucleosides thymidine, uridine and inosine, triggered 
Table 3 Carbon sources specific to $P$. arrhenomanes and/or $P$. graminicola, and/or shared with $P$. inflatum

\begin{tabular}{|c|c|c|c|}
\hline Carbon source & P. arrhenomanes* & P. graminicola* & P. inflatum* \\
\hline D-alanine & + & - & - \\
\hline D-serine & + & - & - \\
\hline Itaconic acid & + & - & - \\
\hline L-threonine & + & - & - \\
\hline Formic acid & + & + & - \\
\hline Hydroxy-L-proline & + & + & - \\
\hline a-ketobutyric acid & + & + & - \\
\hline Citric acid & + & - & + \\
\hline D-galactose & + & - & + \\
\hline D-mannitol & + & - & + \\
\hline D-sorbitol & + & - & + \\
\hline L-serine & + & - & + \\
\hline $\begin{array}{l}\mathrm{N} \text {-acetyl- } \\
\text { D-galactosamine }\end{array}$ & + & - & + \\
\hline Pyruvic acid & + & - & + \\
\hline $\begin{array}{l}\text { Pyruvic acid } \\
\text { methyl ester }\end{array}$ & + & - & + \\
\hline Succinamic acid & + & - & + \\
\hline Xylitol & + & - & + \\
\hline Adonitol & - & + & + \\
\hline $\begin{array}{l}\text { Bromosuccinic } \\
\text { acid }\end{array}$ & - & + & + \\
\hline D-arabitol & - & + & + \\
\hline Lactulose & - & + & + \\
\hline
\end{tabular}

* + or - indicate if the Pythium spp. could respectively grow or not on the according carbon sources. Statistical analyses were performed using

Kruskal-Wallis non-parametric tests in SPSS 21 (SPSS Inc.) $(\alpha=0.05, P \leq \alpha)$.

the growth of $P$. arrhenomanes PT 60, while $P$. inflatum PT 52 seemed to be the only tested isolate that could grow on putrescine.

\section{Discussion}

In this study, one isolate each of $P$. arrhenomanes, $P$. graminicola and $P$. inflatum from diseased aerobic rice fields [3] were selected for a detailed in vitro analysis of their host infection process and the consequent disease development. In vitro inoculation of rice seedling roots revealed that the $P$. arrhenomanes isolate was clearly more virulent than the isolates of $P$. graminicola and $P$. inflatum. This pathogen inhibited crown and lateral root development, induced severe wilting and caused strong stunting of rice roots and shoots, whereas the disease symptoms induced by the $P$. graminicola isolate were less pronounced and the $P$. inflatum isolate exerted only minor effects on rice seedling development.

Histopathological studies revealed that the three Pythium isolates invaded rice seedling roots using penetration hyphae. Once inside the root tissue, Pythium hyphae became irregularly inflated and grew mainly intracellular. Cell wall crossing occurred by means of constricted hyphae, which probably migrated through the plasmodesmata and hence, avoided visible cell wall damage. Consistent findings were presented for Pythium root infections in other monocots [5,6,9]. However, specialized appressoria-like structures instead of simple hyphae enabled rhizodermal penetration in these cases [5]. After pathogen ingress, we found that the $P$. arrhenomanes, $P$. graminicola and $P$. inflatum isolates massively parasitized the inner rice root tissues by hyphal ramification, resulting in the complete filling of cortical and endodermal cells within 27 hpi. Comparably, dense hyphal networks were noted upon infection of Arabidopsis plantlets with P. irregulare [10].

In parallel with their varying virulence, we showed that the three Pythium isolates differed in the extent to which systemic tissues were colonized. The isolate of $P$. arrhenomanes quickly colonized the entire primary root, efficiently spreading from the primary infection site to other parts.

Besides, hyphae abundantly invaded the xylem and accordingly, might have blocked the water transport to the shoot, partly explaining the severe wilting and frequent death of rice seedlings upon inoculation with this isolate. Such parasitic features are common for true vascular pathogens like Fusarium oxysporum and Verticillium spp., where hyphae invade the plant root stele before the endodermis is suberized [11]. In case of Pythium infections, however, hyphal blocking of xylem has not often been reported. Extensive invasion of the vascular stele has only been described for $P$. irregulare on Arabidopsis [10], P. tracheiphilum on lettuce [12], P. sylvaticum and P. dissotocum on strawberry [13] and P. ultimum on cucumber [14]. In the latter case, xylem vessels were also occluded by the production of plant defense-related tyloses that attempted to limit hyphal spread.

The systemic spread of the P. inflatum and, to a lesser extent, the P. graminicola isolate, in the cortex and stele of rice seedling roots, was more limited than that of the $P$. arrhenomanes isolate. Especially xylem vessels appeared less colonized by the $P$. graminicola isolate, whereas the growth of the P. inflatum isolate was often limited to few phloem cells, possibly underlying the lower degree of wilting and stunting upon inoculation with these pathogens. Our $\mathrm{qPCR}$ analysis confirmed that the P. arrhenomanes isolate was the best colonizer of the rice seedling root system, followed by the isolates of $P$. graminicola and $P$. inflatum, with the latter barely spreading in the inner tissues. Such a positive correlation between Pythium root colonization capacity and virulence is not always to be expected. In contrast to our results, Modjehi et al. (1991) [5] reported that in wheat roots, most $P$. arrhenomanes hyphae are blocked at the endodermis. In this study, the 
stele remained unaffected at distance of the primary infection site until the cells died. Moreover, the colonization process of $P$. arrhenomanes proceeded more slowly in this host than in rice roots. Other contrasting findings have been described for Pythium group F-tomato root interactions. Pythium group $\mathrm{F}$ is a minor pathogen that may cause yield losses without producing visible root symptoms [15]. In tomato roots, it is able to colonize all cell types, including the xylem, within 2-3 dpi. However, it has been discovered that most of the xylem-invading hyphae appear as empty ghost cells.

Similar findings have been reported for the biocontrol agent and growth-promoting species $P$. oligandrum in its interaction with tomato roots [16].

The progressive invasions of Pythium hyphae in rice seedling roots triggered the production of reactive oxygen species (ROS) and phenolic compounds, which ultimately evoked cell death. ROS are short-lived molecules that interact with proteins, DNA, lipids and carbohydrates in plant cells, and thereby induce tissue damage and cell death [17]. Plants produce scavengers for anti-oxidative protection. However, several biotic and abiotic factors may disturb the balance between ROS and scavengers, and so, evoke an oxidative burst [18]. Necrotrophic pathogens for instance, may trigger the intracellular production of ROS during the killing of host tissues. On the other hand, ROS-production may as well be part of plant defense responses to biotrophic and hemi-biotrophic pathogens [17]. In the current study, production of hydrogen peroxide $\left(\mathrm{H}_{2} \mathrm{O}_{2}\right)$ was observed in the outer cell layers of Pythium-inoculated rice tissues and was stronger for the more virulent species at 1 dpi. Oliver et al. (2009) [19] also noticed ROS production upon $P$. irregulare and $P$. debaryanum infection of moss, but in theses cases, ROS accumulated in the Pythium-spreading area, where it preceded cell death. The three Pythium isolates invaded the stele of rice seedling roots by $1 \mathrm{dpi}$, while DAB concentrated far behind the infection front, suggesting that the observed $\mathrm{H}_{2} \mathrm{O}_{2}$ accumulation might be related to immune reactions that arose too late to prevent infection. These likely included cell wall modification events, since Pythium spp., like other oomycetes, directly penetrate their host [19] and hydrogen peroxide is involved in the peroxidase-catalyzed cross-linking of cell wall polymers [20]. However, it is also possible that the $\mathrm{H}_{2} \mathrm{O}_{2}$ accumulation in Pythium-infected rice roots was indicative for cell death upon nutrient depletion [21]. Such a trailing necrosis has also been described for $P$. irregulare-Arabidopsis interactions [10]. Histological analyses of $P$. arrhenomanes-inoculated rice cultures revealed cell collapse in the root cortex at $3 \mathrm{dpi}$, which confirmed the occurrence of necrosis.

Cell collapse resulting from $P$. arrhenomanes infections of wheat seedlings has been previously linked with toxin or enzyme production [5]. Toxins or substantial amounts of cell wall degrading enzymes are likely not involved in the Pythium-rice interaction, because pathogen invasion was not associated with extensive tissue damage and was not preceded by cell death. In root tissues inoculated with the $P$. inflatum and $P$. graminicola isolates, we also detected a cortex-related ROS production at 3 dpi that slowed down the Pythium colonization process, suggesting that cell wall strengthening occurred and that the interaction between rice roots and $P$. inflatum or P. graminicola might be less compatible than with $P$. arrhenomanes.

Beside ROS, phenolic compounds fulfill major roles in the response of plants to biotic and abiotic stresses [22]. Pythium infections have been mentioned to elicit the accumulation of phenolics $[16,19]$, which can be incorporated into the cell wall during fortification events or may be liberated during cell death [19]. These phenolic accumulations are microscopically visible as autofluorescence upon UV-irradiation [22] or macroscopically as root browning [23]. In the present paper, we detected a similar root browning in Pythium-inoculated rice cultures. When inner root tissues were studied, we noted the strongest autofluorescence in the cortex of primary roots inoculated with the $P$. arrhenomanes isolate, while autofluorescence was mainly emitted from the sclerenchyma upon inoculation with the $P$. graminicola isolate and was weakly visible in the outer tissues upon inoculation with the $P$. inflatum isolate. Taken together, these results suggest that rice seedlings might respond more and/or faster to highly virulent than weakly virulent Pythium species.

Elevated expression levels of necrosis marker OsJAmyb in Pythium-inoculated rice roots provided molecular support for the induced necrosis that accompanied successive accumulation of $\mathrm{H}_{2} \mathrm{O}_{2}$ and phenolic compounds. Analyses of the transcript levels at various times suggested that infections with the $P$. arrhenomanes isolate may have induced a higher degree of necrosis, confirming the higher susceptibility of rice seedlings to this pathogen [8], while the induction of necrosis might have been delayed or weaker upon inoculation with the $P$. inflatum isolate.

The activation of this jasmonic acid (JA)-responsive gene also implies a role for the JA response in the Pythium-rice interaction. Many papers have reported on the defense-inducing role of jasmonates (JAs) in Pythiumdicot interactions $[10,19,24]$. In rice, however, salicylic acid (SA) and gibberellic acid (GA) pathways have been identified as regulators of root defense to Pythium spp. [4]. The latter research also revealed the ability of $P$. graminicola to hijack the brassinosteroid (BR) machinery in rice seedling roots and hence, negate GA- and SA-dependent immune responses. This seemed to be paralleled with the indirect stabilization of the GA-repressor SLENDER 
RICE1 (SLR1), i.e. the rice DELLA protein. Interestingly, a recent paper by Yang et al. (2012) [25] reported on the antagonism between JA and GA in rice, and described the DELLA-stabilizing effect of JA. Based on these findings, we put forth a possible model in which Pythium infection directly or indirectly activates the JA pathway in rice, by which SLR1 is stabilized and roots become more susceptible. A similar negative role for JA has only been detected in Fusarium oxysporum-Arabidopsis interactions, where the pathogen hijacks COI-mediated JA signaling to promote disease development [26]. More research is required to verify this hypothesis and uncover the role of JA in the Pythium-rice pathosystem.

Since the virulence and root colonization capacity of rice-infecting Pythium spp. seems to be positively linked, we compared the nutritional profiles of the $P$. arrhenomanes, P. graminicola and P. inflatum isolates to elucidate whether highly virulent species could be physiologically more adapted to their colonization niche or could use specific nutrients as a defense strategy. It was interesting to see that the nutritional profiles of the highly virulent $P$. arrhenomanes and moderately virulent $P$. graminicola isolates were quite similar and clearly different from that of the weakly virulent $P$. inflatum isolate. Carbonutilization patterns proposed $P$. inflatum as nutritionally the most versatile species. Similar findings were obtained from comparative analyses between plant pathogenic and non-pathogenic Pseudomonas species, in which pathogenic species exhibited reduced nutritional versatility [27].

Especially the carbohydrate-utilization profile of the $P$. inflatum isolate was more extensive than that of the $P$. arrhenomanes and $P$. graminicola isolate. Nevertheless, the three Pythium isolates grew very well on sucrose, maltose, gentiobiose, D-cellobiose and $\alpha$-D-glucose and furthermore, $P$. arrhenomanes and $P$. graminicola isolates strongly multiplied on the storage polysaccharide glycogen, and $\mathrm{D}$-trehalose and $\mathrm{D}$ fructose, respectively. These carbohydrates were among those previously mentioned as growth-stimulators of P. aphanidermatum [28], P. myriotylum, P. dissotocum, $P$. arrhenomanes [29] and P. oligandrum [30], and which represent, together with other carbohydrates, the largest part of the rice rhizodeposition [31]. In addition, $P$. inflatum and $P$. arrhenomanes isolates were able to grow on D-galactose, which is abundantly exuded by rice roots [32]. Hence, we hypothesize that especially $P$. inflatum and P. arrhenomanes and to a lesser extent $P$. graminicola might be physiologically adapted to use carbohydrates likely to be present in the rice rhizosphere. This may also explain the stronger superficial colonization of rice tissues by the $P$. arrhenomanes and $P$. inflatum isolates during our in vitro analysis.

The tested $P$. inflatum isolate also exhibited the broadest carboxylic acid-utilization pattern. Malic acid, citric acid and formic acid are known to be present in the phloem sap of rice plants [33] and because our data illustrated that $P$. inflatum, $P$. arrhenomanes and/or $P$. graminicola isolates could grow on these carbon sources, they might serve as nutrient sources inside the rice root stele. The intracellular uptake of these nutrients might have proceeded via haustoria-like structures, which have been described for P. irregulare on Arabidopsis [10].

In contrast to the Pseudomonas study where plant pathogenic species showed to be specialized in the use of the six most abundant amino acids in their primary infection site [27], we noted that the most virulent Pythium isolate exhibited the broadest amino acid-utilization pattern. All Pythium isolates were able to grow on a consistent group of nine amino acids that have been proven to attract Pythium zoospores [34], stimulate the zoospore encysting process [34] and/or promote the growth of various Pythium spp. [28-30].

Among these, especially histidine, proline and alanine are exuded by rice seedlings during the first weeks after planting [32], and asparagine and glutamate are present in the rice phloem [35]. Accordingly, these carbon sources may be used during the outer and inner root colonization processes of the $P$. arrhenomanes, $P$. graminicola and/or $P$. inflatum isolates in our in vitro experiments. It was interesting to see that the amino acid-profile of the $P$. arrhenomanes isolate also consisted of $\mathrm{D}$-serine and D-alanine. Up to date, no Pythium spp. have been documented to grow on D-enantiomers of amino acids. Since rice seeds contain substantial amounts of D-serine [36], and D-alanine peptides are present in rice tissues [37], this exceptional feature may contribute to the massive colonization of rice seeds and seedling roots by the P. arrhenomanes isolate.

The selective utilization of amino acids is not always a nutritional preference. It might also represent a virulence strategy through which pathogens try to lower defense-related compounds [38]. Hydroxyl-L-proline and L-threonine are building blocks of hydroxyprolinerich glycoproteins (also called extensins), which are present in the primary cell wall of monocots [39] and are functionally implicated in cell wall extension and peroxidase-mediated cell wall fortification [39]. The screened isolates of $P$. arrhenomanes and $P$. graminicola showed to grow on respectively both amino acids and hydroxyl-L-proline only, which may suggest that $P$. arrhenomanes has a stronger potential to block cell wall strengthening in rice root tissues. However, our histopathological study did not evidence the inhibition of cell wall fortification events during Pythium-infections of rice seedlings, but their occurrence could have been delayed. Aside from this, L-threonine represents one of the dominant free amino acids in the rice phloem sap [35] and may exert growth-suppressive effects during the 
interaction of plants with obligate biotrophic oomycetes [40]. It might be possible that $P$. arrhenomanes attempts to remove L-threonine from its host tissues to increase its fitness, but this hypothesis needs further investigation.

In our phenoarrays, we also noted that the three Pythium isolates used the defense-related amino acid L-proline [41,42]. Additionally, the $P$. inflatum isolate seemed to grow on putrescine, a stress-related polyamine. Since the weakest virulent isolate could grow on both carbon sources, their removal from the environment is probably not determining for the aggressiveness level of rice-pathogenic Pythium spp.

\section{Conclusions}

The degree by which Pythium spp. can feed on amino acids, and invade rice cortical and stelar cells seems to be related with the intensity of Pythium-induced stunting and wilting symptoms in rice seedlings. Our data suggest that highly virulent Pythium species quickly and massively colonize rice root tissues, probably by suppressing cell-wall fortification events, removing defenserelated compound from rice tissues, and growing on D-amino acids of which rice seeds contain substantial amounts. Quick invasion of the vascular stele might be of utmost importance for the virulence level of riceinfecting Pythium spp., since the rice root endodermis and vascular tissues become suberized/lignified during maturation [43]. This could explain why rice seedlings acquire a certain degree of Pythium-resistance within eight days after planting [44]. Interestingly, gibberellins have been noted to mediate lignification of monocot roots [45]. Since GA induces Pythium-resistance in rice seedlings, this might reveal why pathogenic Pythium spp. try to suppress the GA pathway by inducing the counteracting BR-pathway in rice seedling roots [4]. In this way, they may counterbalance or postpone cell wall fortification in rice seedling roots, i.e. the most important defense reactions against oomycetes.

\section{Methods}

\section{Pythium isolates}

In this study, we selected one isolate each of $P$. arrhenomanes, $P$. graminicola and $P$. inflatum to study the interaction between Pythium and rice (Table 4). These isolates exhibited different levels of virulence under in vitro conditions [3]. Isolates were cultured on $22 \mathrm{ml}$ of potato dextrose agar (PDA; Difco Laboratories) at $28^{\circ} \mathrm{C}$ in the dark.

\section{Plant material and infection trials}

The rice cultivar Nipponbare (O. sativa subspecies japonica) was selected for the in vitro monitoring of disease symptoms caused by $P$. arrhenomanes, $P$. graminicola and $P$. inflatum on rice roots and shoots. Seeds were as susceptible to Pythium as the aerobic rice cv. 'Apo', the original host. Prior to germination, seeds were disinfected by agitation in $70 \% \mathrm{EtOH}(1 \mathrm{~min})$ and $2 \% \mathrm{NaOCl}$ (15 min). After three successive rinses in sterile demineralized water and blotting on sterile filter paper, surface-sterilized seeds were plated on square Petri dishes $(120 \times 120 \mathrm{~mm})$ filled with $50 \mathrm{ml}$ of Gamborg B5 (GB5) medium [46]. Plates were incubated at $28^{\circ} \mathrm{C}$ in the dark for three days. Subsequently, seedlings with equal primary root lengths $(1.5 \mathrm{~cm})$ were selected and 6 seedlings were transplanted $2 \mathrm{~cm}$ apart on fresh GB5 plates. Three mycelial plugs ( $5 \mathrm{~mm}$ in diameter) taken from the edge of a three-day-old $P$. arrhenomanes, $P$. graminicola or $P$. inflatum colony were placed between the roots of seedlings 1-2, 3-4 and 5-6. Square Petri dishes were partly covered with aluminum foil to shield the roots from light and then, incubated in upright position $\left(60^{\circ} \mathrm{C}\right.$ angle) inside a growth chamber with a $12 \mathrm{~h}$ day $\left(28^{\circ} \mathrm{C}\right) /$ night $\left(26^{\circ} \mathrm{C}\right)$ cycle. The experiment consisted of three replications per treatment.

For disease evaluation, maximal root and shoot lengths were measured ten days post inoculation (dpi) $(n=18)$. Disease symptoms on rice shoots were rated on the basis of a disease severity scale (Figure 9) $(\mathrm{n}=3)$ : score 0 , healthy shoots; score 1 , shoot length $\geq 50 \%$ of the control, green culm and few yellow or brown spotted leaves; score 2 , shoot length $\geq 34 \%$ of the control, slightly yellowing culm and yellow or brown spotted leaves; score 3 , shoot length $<34 \%$ of the control, slightly yellowing culm and yellow or brown spotted leaves; score 4, shoot length $<34 \%$ of the control, yellow culm and yellow or brown leaves; score 5 , shoot length $<34 \%$ of the control, brown, dried-out culm and leaves. This scale enabled us to calculate the disease severity index (DSI) for each biological replicate (i.e. Petri dish) using the following equation: $(((\# \times$ score 0$)+(\# \times$ score 1$)+(\# \times$ score 2$)+$ $(\# \times$ score 3$)+(\# \times$ score 4$)+(\# \times$ score 5$)) /(($ total $\#) \times$

Table 4 Origin of the Pythium strains that were used in this study

\begin{tabular}{lcccc}
\hline \multicolumn{1}{c}{ Species } & Isolate & Geographic origin & Year of isolation & Collection no. $^{\mathbf{a}^{2}}$ \\
\hline P.arrhenomanes & PT 60 & The Philippines, Tarlac (Dapdap) & 2007 & MUCL52737 \\
P. graminicola & PB912 132 & The Philippines, Los Baños (IRRI) & 2008 & MUCL53742 \\
P. inflatum & PT 52 & The Philippines, Tarlac (Dapdap) & 2007 & MUCL53750 \\
\hline
\end{tabular}

${ }^{a} \mathrm{All}$ isolates were recovered from the roots of aerobic rice plants [3]. 
score 5)) $) \times 100$ (with \# the no. of seedlings). Most data were not normally distributed and statistically analyzed with Kruskal-Wallis and Mann-Whitney non-parametric tests in SPSS 21 (SPSS Inc.) $(\alpha=0.05, P \leq \alpha)$. Data that were normally distributed were analyzed by one-way ANOVA and a Duncan Post-Hoc test $(\alpha=0.05, P \leq \alpha)$.

\section{Microscopic analysis of root samples}

Root infection processes were analyzed at various times after $P$. arrhenomanes, $P$. graminicola and $P$. inflatum inoculation using bright field and epifluorescence microscopy. In this experiment, GB5-culture plates contained four rice seedlings next to which four mycelial plugs were placed at $0.5 \mathrm{~cm}$ distance at the right side of each emerging radicle. Parts of the primary roots showing superficial hyphal growth and necrosis were excised from Pythium-inoculated rice seedlings. Root samples of $\pm 0.5 \mathrm{~cm}$ were fixated in a $50 \mathrm{mM}$ sodium phosphate buffer ( $\mathrm{pH} 7.2$ ) containing 4\% paraformaldehyde and 1\% glutaraldehyde, and subsequently dehydrated in a graded series of EtOH and infiltrated with Technovit 7100 solution.

The infiltrated root samples were finally embedded in plastic $1 \mathrm{~cm}^{2}$ - cubes filled with Technovit 7100 histo-embedding medium (Heraeus Kulzer, Wehrheim, Germany). A Leica RM2265 motorized rotary microtome (Leica Microsystems, Nussloch, Germany) was used to produce $5 \mu \mathrm{m}$ cross-sections. For each treatment at different time points, three to four root samples of at least two different seedlings were entirely sectioned. This resulted into 50 cuttings per sample, which were randomized on ten microscopic slides. At least two slides were chosen for each staining procedure. Pythium hyphae were stained by incubation of sections in $0.1 \%(\mathrm{w} / \mathrm{v})$ trypan blue in $10 \%(\mathrm{v} / \mathrm{v})$ acetic acid for $5 \mathrm{~min}$. The accumulation of phenolic compounds was visualized by staining with $0.1 \%$ Fluorescent brightener 28 (Calcofluor White M2R) for $1 \mathrm{~min}$. All stained sections were thoroughly rinsed, dried and mounted with neutral mounting medium (DPX, Klinipath, Belgium). The accumulation of hydrogen peroxide $\left(\mathrm{H}_{2} \mathrm{O}_{2}\right)$, a marker for plant defense and induced necrosis, was demonstrated by staining of fresh root samples with 3,3'-diaminobenzidine (DAB). Three to four root samples were collected from at least two different seedlings for each treatment at various time points. Immediately after sampling, vacuum-infiltration with a $0.1 \%$ 3,3'-diaminobenzidine (DAB)-solution ( $\mathrm{pH} 4.4$ ) was performed in three successive steps of $5 \mathrm{~min}$ in the dark. After an extra incubation step of $4 \mathrm{~min}$, the residual stain was removed and the samples were fixated, sectioned and mounted as described above. The DAB-stained specimens were also treated with trypan blue to visualize Pythium hyphae. Digital images were acquired with an Olympus BX51 microscope equipped with an Olympus ColorView III Camera and Xenon light source. A DAPI narrow-band fluorescence cube (BP330-385 nm/DM400/BA420) was selected for analyses with the fluorescent stain. Images were processed with the Olympus analysis cell^ $\mathrm{F}$ software (Olympus Soft Imaging Solutions, Münster, Germany) and ImageJ $1.44 \mathrm{p}$.

\section{Quantitative detection of Pythium spp. in root samples}

Primers specific for the multi-copy Internal Transcribed Spacer (ITS)-region of the ribosomal DNA (rDNA) of P. arrhenomanes PT 60, P. graminicola PB912 132 and P. inflatum PT 52 were constructed using PrimerBLAST (NCBI) and OligoAnalyzer 2.1. web-software (IDT, Coralville, IA) (Table 5). The species specificity

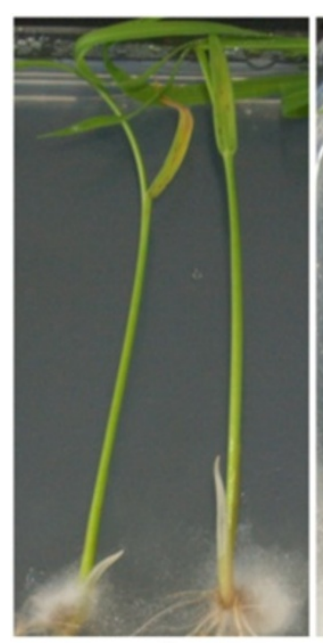

1

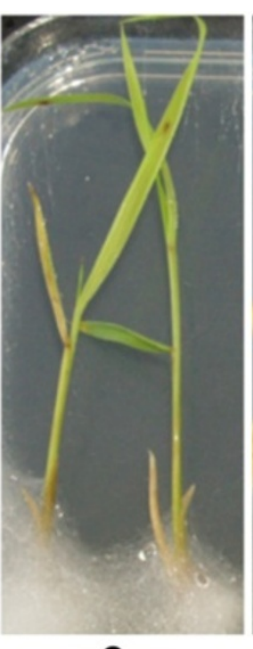

2

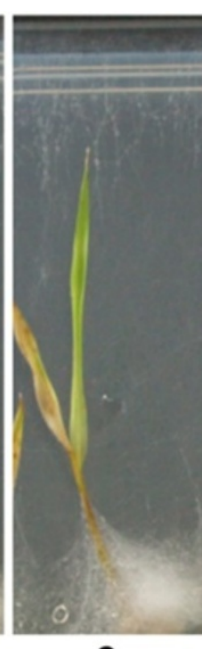

3
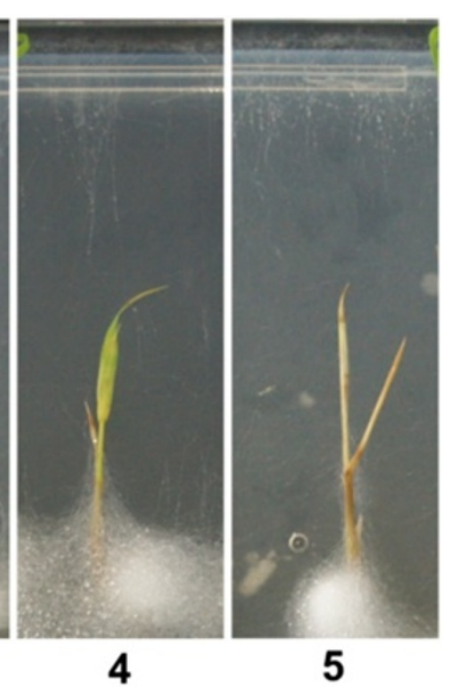

Figure 9 The disease severity scale implemented for disease rating on rice shoots. Shoot disease severity scores (1-5) are based on the degree of stunting and wilting. 
Table 5 Sequences of the species-specific primers that amplify a part of the ITS1 region

\begin{tabular}{|c|c|c|c|c|}
\hline Pythium isolate & Forward ITS primer $\left(5^{\prime}-3^{\prime}\right)^{a}$ & Reverse ITS primer $\left(5^{\prime}-3^{\prime}\right)^{a}$ & Size amplicon & GenBank Accession no. $^{b}$ \\
\hline P. arrhenomanes PT 60 & $\begin{array}{c}\text { ATTCTGTACGCGTGGTCTTCCG } \\
(3 \mu \mathrm{M})\end{array}$ & $\begin{array}{c}\text { ACCTCACATCTGCCATCTCTCTCC } \\
(1 \mu \mathrm{M})\end{array}$ & $311 \mathrm{bp}$ & HQ877857 \\
\hline P. graminicola PB912 132 & $\begin{array}{c}\text { ATGGCTGAACGAAGGTGGGCTG } \\
(1 \mu \mathrm{M})\end{array}$ & $\begin{array}{c}\text { TCCCGAAAGTGCAATGTGCGTTC } \\
(3 \mu \mathrm{M})\end{array}$ & $240 \mathrm{bp}$ & HQ877865 \\
\hline P. inflatum PT 52 & $\begin{array}{c}\text { AGGTGGGCGCATGTATGTGTGTC } \\
(500 \mathrm{nM})\end{array}$ & $\begin{array}{c}\text { ACGTATCGCAGTTCGCAGCG } \\
(3 \mu \mathrm{M})\end{array}$ & $165 \mathrm{bp}$ & HQ877856 \\
\hline
\end{tabular}

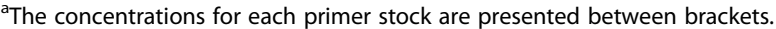

${ }^{\mathrm{b}}$ The ITS-regions of P. arrhenomanes PB912 75 (HQ877857) and P. graminicola PB912 116 (HQ877865) are respectively identical to those of $P$. arrhenomanes PT 60 and P. graminicola PB912 132 [3].

of the primers was double-checked with pure DNA of the three Pythium spp. and rice root DNA (cv. Nipponbare). Optimal annealing temperatures were assessed by gradient PCR on a thermal cycler (Flexcycler, Analytikjena) and a primer titration was executed on a Mx3005P real-time PCR detection system (Stratagene) using Sybr Green master mix (Fermentas). After setting the optimal reaction conditions, standard curves based on quinquepartite dilution series (10 ng - $1 \mathrm{pg}$ ) were run on the real-time PCR to monitor the amplification efficiency and accuracy of the primer pairs. If the curves showed $R^{2} \geq 0.985$, slopes between -3.1 à -3.6 and efficiencies between 90-110\%, primers were accepted.

Pythium-inoculated rice roots were collected at different time points from rice-seedling culture plates, in two separate experiments (see "Plant material and infection trials"). In each experiment, samples from two replicate plates were pooled per treatment at each time point $(n=2)$. Samples were immediately frozen in liquid nitrogen or prior to freezing surface-sterilized in $1 \% \mathrm{NaOCl}$ for $1 \mathrm{~min}$ and thoroughly washed. Next, DNA was extracted from the finely crushed roots with the DNeasy Plant Mini Kit (QIAGEN). The quality and concentration of the extracted DNA was determined with a ND-1000 spectrophotometer (NanoDrop). If necessary, ethanol precipitation was applied to concentrate the DNA sample. The extracted DNA $(2.5 \mu \mathrm{l}$ of $1 \mathrm{ng} / \mu \mathrm{l})$ was added to 96 -well plates, filled with $12.5 \mu \mathrm{l}$ aliquots of Sybr Green master mix (Fermentas) that were supplemented with $2.5 \mu \mathrm{l}$ of each primer stock solution (Table 2), $0.05 \mu \mathrm{l}$ of ROX solution and $4.95 \mu \mathrm{l}$ of nuclease-free water. Each DNA sample was analyzed in duplicate with the Mx3005P real-time PCR detection system (Stratagene) using the following thermal profile: an initial denaturation at $95^{\circ} \mathrm{C}$ for $10 \mathrm{~min}$, and 40 cycles of $15 \mathrm{~s}$ at $95^{\circ} \mathrm{C}, 30 \mathrm{~s}$ at $63^{\circ} \mathrm{C}$ and $15 \mathrm{~s}$ at $72^{\circ} \mathrm{C}$. To verify amplicon specificity, a default meltingcurve analysis (Stratagene) was included. Finally, cycle threshold $(\mathrm{Ct})$ values $(\mathrm{n}=4)$ were implemented in the standard curves' equations to quantify the amount of Pythium DNA in the collected root samples.

Gene expression analysis in Pythium-inoculated rice roots Rice roots were collected from GB5-culture plates at different times upon Pythium inoculation (see "Plant material and infection trials"). In each of three experiments, root samples from two replicate plates were pooled per treatment at each time point $(n=3)$. Samples were frozen in liquid nitrogen, finely crushed and afterwards, total RNA was extracted using the spectrum plant total RNA kit (Sigma-Aldrich). A Turbo Dnase treatment (Ambion) was immediately performed and the quality and concentration of the extracted RNA was determined with a ND-1000 spectrophotometer (NanoDrop). Next, complement DNA (cDNA) was synthesized from the total RNA (10 ng/ $\mu$ l) with Multiscribe reverse transcriptase and random primers (Applied Biosystems). This cDNA $(2.5 \mu \mathrm{l}$ of $10 \mathrm{ng} / \mu \mathrm{l})$ was added to 96-well plates, filled with $12.5 \mu$ l aliquots of Sybr Green master mix (Fermentas) that were supplemented with $2.5 \mu \mathrm{l}$ of each primer stock solution (Table 3), $0.05 \mu \mathrm{l}$ of ROX solution and $4.95 \mu \mathrm{l}$ of nuclease-free water. Each sample was analyzed in duplicate with the Mx3005P real-time PCR detection system (Stratagene) under the following conditions: an initial denaturation step at $95^{\circ} \mathrm{C}$ for $10 \mathrm{~min}$, and 40 cycles of $15 \mathrm{~s}$ at $95^{\circ} \mathrm{C}, 30 \mathrm{~s}$ at $59^{\circ} \mathrm{C}$ and $15 \mathrm{~s}$ at $72^{\circ} \mathrm{C}$. After the PCR, a default melting curve (Stratagene) was generated to test amplicon specificity. The quantity of plant RNA in each sample was normalized using OsACTIN1 (LOC_Os03g50890) as internal reference (Table 6). Ct values were relatively

Table 6 Sequences of the used primers for gene expression analysis

\begin{tabular}{|c|c|c|c|}
\hline Gene & Forward primer $\left(5^{\prime}-3^{\prime}\right)^{a}$ & Reverse primer $\left(5^{\prime}-3^{\prime}\right)^{a}$ & GenBank Accession no. \\
\hline OsJAmyb & GAGGACCAGAGTGCAAAAGC $(3 \mu \mathrm{M})$ & CATGGCATCCTTGAACCTCT (3 $\mu \mathrm{M})$ & AY026332 \\
\hline OsACTIN1 & GCGTGGACAAAGTTTCAACCG $(1 \mu \mathrm{M})$ & TCTGGTACCCTCATCAGGCATC (3 $\mu \mathrm{M})$ & X15865 \\
\hline
\end{tabular}

${ }^{\mathrm{a}}$ The concentrations for each primer stock are presented between brackets. 
expressed to the non-inoculated control at $1 \mathrm{dpi}$ and the average fold change of the three experiments $(n=3)$ was calculated.

\section{Phenoarrays}

The carbon-utilization patterns of pure $P$. arrhenomanes, $P$. graminicola and $P$. inflatum cultures were investigated in vitro with SF-N2 and SF-P2 MicroPlates (Biolog Inc.) based on the protocol of Chun et al. (2003) [30]. In these MicroPlates, each well contains a nutrient base with specific carbon sources, including several carbohydrates, amino acids and carboxylic acids. Pythium strains were cultured in $50 \mathrm{ml}$ of potato dextrose broth (PDB; Difco Laboratories) at $28^{\circ} \mathrm{C}$ in the dark. After 11 days, liquid cultures were filtered with sterile sieving cloth $(1 \mathrm{~mm}$ mesh) and the retained mycelial mats were washed in three rinses with sterile demineralized water. The harvested mycelium was subsequently mixed in a sterile $1 \mathrm{mM}$ potassium phosphate buffer $(\mathrm{pH}=7)$ and again sieved (1 mm mesh). Optical densities of the suspensions were determined at $595 \mathrm{~nm}$ in triplicate using a Multiscan EX spectrophotometer (Thermo Labsystems). Next, OD's were adjusted to $0.100 \pm 0.006$ by dilution in sterile phosphate buffer, and three SF-N2 and three SF-P2 MicroPlates were filled with $100 \mu \mathrm{l}$ aliquots of each mycelial suspension. Control plates were filled with $100 \mu \mathrm{l}$ aliquots of sterile phosphate buffer. Upon an incubation step of $24 \mathrm{~h}$ at $28^{\circ} \mathrm{C}$ in the dark, carbon source utilization patterns of P. arrhenomanes PT 60, P. graminicola PB912 132 and $P$. inflatum PT 52 were assessed by turbidity measurements at $595 \mathrm{~nm}$. The experiment consisted of three replicate plates and was repeated in time to verify the reproducibility. This generated at least six OD-values per carbon source for each treatment $(n \geq 6)$. Data were statistically analyzed using Kruskal-Wallis in SPSS 21 (SPSS Inc.) $(\alpha=0.05, P \leq \alpha)$. When turbidities significantly exceeded the initial OD $(=0.1)$, Pythium spp. were assumed to use the according carbon sources for their growth.

\section{Additional files}

Additional file 1: Figure S1. The stimulating effect of rice seed exudates on Pythium growth. Rice seeds ( $2.5 \mathrm{~g})$ of the Cv. CO-39 (O. sativa subspecies indica), which is as susceptible to Pythium as Cvs. Apo and Nipponbare, were surface sterilized, washed and incubated in $20 \mathrm{ml}$ of sterile demineralized water at $28^{\circ} \mathrm{C}$. Seed exudates were collected as a watery solution after $24 \mathrm{~h}$ of imbibition. Three $\mathrm{ml}$ aliquots of water (-) or exudate solutions (+) were added to three six-well replicate plates and afterwards, inoculated with one PDA plug of a four-day old $P$. arrhenomanes, $P$. graminicola or $P$. inflatum culture. Plates were incubated at $28^{\circ} \mathrm{C}$ and screened after $17 \mathrm{~h}$. A clear stimulation in colony diameter and/or density was visible when Pythium spp. were grown in seed exudates. The picture is representative for the three replicate plates.

Additional file 2: Table S1. Carbon sources that stimulated Pythium growth in the phenoarray. Data represent the carbon sources for which the OD-values significantly differed from the initial OD $(=0.1)$ at $24 \mathrm{hpi}$ according to Kruskal-Wallis non-parametric tests in SPSS 21 ( $a=0.05$, $P \leq a$ ). Values between brackets represent standard errors.

Additional file 3: Table S2. Carbon sources that did not stimulate growth of Pythium in the phenoarray. The OD-values of the listed carbon sources did not significantly differ from the initial OD $(=0.1)$ at $24 \mathrm{hpi}$ according to Kruskal-Wallis non-parametric tests in SPSS $21(\alpha=0.05$, $P \leq \mathrm{a})$.

\section{Competing interests}

The authors declare that they have no competing interests.

\section{Authors' contributions}

VBE carried out the experiments, interpreted the data, drafted and edited the manuscript. HM coordinated the interpretation of data and drafting, revised the manuscript critically and gave final approval for publication. Both authors read and approved the final manuscript.

\section{Acknowledgements}

This study was supported by a specialization fellowship from the Flemish Institute for the Promotion of Innovation by Science and Technology in Flanders (IWT-Vlaanderen), by grants from the Special Research Fund of Ghent University (bilateral grant and GOA 01GB3013) and the Research Foundation Flanders (FWO-Vlaanderen project G.0833.12). The authors thank dr. Huang Chien Jui for his help with proofreading.

Received: 21 June 2013 Accepted: 29 November 2013

Published: 5 December 2013

\section{References}

1. Martin FN, Loper JE: Soil-borne plant diseases caused by Pythium spp.: ecology, epidemiology, and prospects for biological control. Crit Rev Plant Sci 1999, 18:111-181.

2. van der Plaats-Niterink AJ: Monograph of the genus Pythium. In Studies in Mycology. Baarn, the Netherlands: Centraalbureau voor Schimmelcultures; 1981:200-239.

3. Van Buyten E, Banaay CGB, Vera Cruz C, Höfte M: Identity and variability of Pythium species associated with yield decline in aerobic rice cultivation in the Philippines. Plant Pathol 2013, 62:139-153.

4. De Vleesschauwer D, Van Buyten E, Satoh K, Balidion J, Mauleon R, Choi IR, Vera-Cruz C, Kikuchi S, Höfte M: Brassinosteroids antagonize gibberellinand salicylate-mediated root immunity in rice. Plant Physiol 2012, 158:1833-1846.

5. Mojdehi H, Singleton LL, Richardson PE: Histopathology of wheat seedling roots infected with Pythium arrhenomanes. J Phytopathol 1991, 132:75-83.

6. Napi-Acedo G, Exconde OR: Penetration and infection of corn roots by Pythium arrhenomanes. Philipp Agric Sci 1965, 49:279-293.

7. Macia-Vicente JG, Jansson H, Lopez-Llorca LV: Assessing fungal root colonization for plant improvement. Plant Signalling Behav 2009, 4:445-457.

8. Lee MW, Qi M, Yang Y: A novel jasmonic acid-inducible rice myb gene associates with fungal infection and host cell death. Mol Plant Microbe Interact 2001, 14:527-535.

9. McKeen WE: Growth of Pythium graminicola in barley roots. Can J Botany 1977, 55:44-47.

10. Adie BAT, Pérez-Pérez J, Pérez-Pérez MM, Godoy M, Sanchez-Serrano JJ, Schmelz EA, Solano R: ABA is an essential signal for plant resistance to pathogens affecting JA-biosynthesis and the activation of defenses in Arabidopsis. Plant Cell 2007, 19:1665-1681.

11. Okubara PA, Paulitz TC: Root defense responses to fungal pathogens: a molecular perspective. Plant Soil 2005, 274:215-226.

12. Matta A: A disease of lettuces produced by a new species of Pythium. Phytopathol Mediterr 1965, 4:48-53.

13. Nemec S: Histopathology of Pythium infected strawberry roots. Can J Botany 1972, 50:1091-1096.

14. Chérif M, Benhamou N, Bélanger RR: Ultrastructural and cytochemical studies of fungal development and host reactions in cucumber plants infected by Pythium ultimum. Physiol Mol Plant P 1991, 39:353-375. 
15. Rey P, Benhamou N, Tirilly: Ultrastructural and cytochemical investigation of asymptomatic infection by Pythium spp. Phytopathology 1998 88:234-244

16. Le Floch G, Benhamou N, Mamaca E, Salerno Ml, Tirilly Y, Rey P: Characterization of the early events in atypical tomato root colonization by a biocontrol agent, Pythium oligandrum. Plant Physiol Bioch 2005 43:1-11.

17. Heller J, Tudzynski P: Reactive oxygen species in phytopathogenic fungi: signaling, development and disease. Annu Rev Phytopathol 2011, 49:369-390.

18. Apel K, Hirt H: Reactive oxygen species: metabolism, oxidative stress, and signal transduction. Annu Rev Plant Biol 2004, 55:373-399.

19. Oliver JP, Castro A, Gaggero C, Cascon T, Schmelz EA, Castresana C, Ponce de Léon I: Pythium infection activates conserved plant defense responses in mosses. Planta 2009, 230:569-579.

20. Brisson LF, Tenhaken R, Lamb C: Function of oxidative cross-linking of cell wall structural proteins in plant disease resistance. Plant Cell 1994 6:1703-1712.

21. Able AJ: Role of reactive oxygen species in the response of barley to necrotrophic pathogens. Protoplasma 2003, 221:137-143.

22. Hutzler P, Fischbach R, Heller W, Jungblut TP, Reuber S, Schmitz R, Veit M, Weissenböck G, Schnitzler J: Tissue localization of phenolic compounds in plants by confocal laser scanning microscopy. J Exp Bot 1998, 49:953-965.

23. Owen-Going TN, Beninger CW, Sutton JC, Hall JC: Accumulation of phenolic compounds in plants and nutrient solution of hydroponically grown peppers inoculated with Pythium aphanidermatum. Can J Plant Pathol 2008, 30:214-225.

24. Staswick PE, Yuen GY, Lehman CC: Jasmonate signaling mutants of Arabidopsis are susceptible to the soil fungus Pythium irregulare. Plant J 1998, 15:747-754

25. Yang D, Yao J, Mei C, Tong X, Zeng L, Li Q, Xiao L, Sun T, Li J, Deng X, Lee CM, Thomashow MF, Yang Y, He Z, He SY: Plant hormone jasmonate prioritizes defense over growth by interfering with gibberellin signaling cascade. Proc Natl Acad Sci USA 2012. doi:10.1073/pnas.1201616109.

26. Thatcher LF, Manners JM, Kazan K: Fusarium oxysporum hijacks COI1-mediated jasmonate signaling to promote disease development in Arabidopsis. Plant J 2009, 58:927-939.

27. Rico A, Preston GM: Pseudomonas syringae pv. tomato DC3000 uses constitutive and apoplast-induced nutrient assimilation pathways to catabolize nutrients that are abundant in the tomato apoplast. Mol Plant Microbe Interact 2008, 21:269-282

28. Khalil S, Alsanius BW: Utilization of carbon sources by Pythium, Phytophthora, Fusarium species as determined by Biolog Microplate assay. Open Microbiol J 2009, 3:9-14.

29. Chun S, Schneider RW, Chung I: Determination of carbon source utilization of Bacillus and Pythium species by Biolog Microplate assay. J Microbiol 2003, 41:252-258.

30. McQuilken MP, Whipps JM, Cooke RC: Nutritional and environmental factors affecting biomass and oospore production of the biocontro agent Pythium oligandrum. Enzyme Microb Tech 1992, 14:106-111.

31. Suzuki K, Okazaki K, Tawaraya K, Osaki M, Shinano T: Gas chromatographymass spectrometry associated global analysis of rice root exudates under aseptical conditions. Soil Sci Plant Nutr 2009, 55:505-513.

32. Bacilio-Jiménez M, Aguilar-Flores S, Ventura-Zapata E, Pérez-Campos E, Bouquelet S, Zenteno E: Chemical characterization of root exudates from rice (Oryza sativa) and their effects on the chemotactic response of endophytic bacteria. Plant Soil 2003, 249:271-277.

33. Hayashi H, Chino M: Nitrate and other anions in the rice phloem. Plant Cell Physiol 1985, 26:325-330.

34. Donaldson SP, Deacon JW: Effects of amino acids and sugars on zoospore taxis, encystment and cyst germination in Pythium aphanidermatum (Edson) Fitzp., P. catenulatum Matthews and P. dissotocum Drechs. New Phytol 1993, 132:289-295.

35. Fukumorita T, Chino M: Sugar, amino acid and inorganic contents in rice phloem sap. Plant Cell Physiol 1982, 23:273-283.

36. Gogami Y, Ito K, Kamitani Y, Matsushima Y, Oikawa T: Occurrence of $\mathrm{D}$-serine in rice and characterization of rice serine racemase. Phytochemistry 2009, 70:380-387.

37. Manabe H: Formation of dipeptides containing D-alanine in wild rice plants. Phytochemistry 1992, 31:527-529.
38. Seifi HS, Van Bockhaven J, Angenon G, Höfte M: Glutamate metabolism in plant disease and defense: friend of foe? Mol Plant Microbe Interact 2013, 26:475-485.

39. Smallwood M, Martin H, Knox JP: An epitope of rice threonine- and hydroxyproline-rich glycoprotein is common to cell wall and hydrophobic plasma membrane glycoproteins. Planta 1995, 196:510-522

40. Stuttmann J, Hubberten HM, Rietz S, Kaur J, Muskett P, Guerois R, Bednarek P, Hoefgen R, Parker JE: Perturbation of Arabidopsis amino acid metabolism causes incompatibility with the adapted pathogen Hyaloperonospora arabidopsis. Plant Cell 2011, 23:2788-2803.

41. Hare PD, Cress WA: Metabolic implications of stress-induced proline accumulations in plants. Plant Growth Regul 1997, 21:79-102.

42. Cassab Gl: Plant cell wall proteins. Annu Rev Plant Physiol Plant Mol Biol 1998, 49:281-309.

43. Clark LH, Harris WH: Observation on the root anatomy of rice (Oryza sativa L.). Am J Bot 1981, 68:154-161.

44. Chun SC, Schneider RW: Sites of infection by Pythium species in rice seedlings and effects of plant age and water depth on disease development. Phytopathology 1998, 88:1255-1261.

45. Biemelt $\mathrm{S}$, Tschiersch $\mathrm{H}$, Sonnewald $\mathrm{U}$ : Impact of altered gibberellin metabolism on biomass accumulation, lignin biosynthesis, and photosynthesis in transgenic tobacco plants. Plant Physiol 2004, 135:254-265.

46. Gamborg OL, Miller RA, Ojima K: Nutrient requirements of suspension cultures of soybean root cells. Exp Cell Res 1968, 50:151-158.

\section{doi:10.1186/1471-2229-13-203}

Cite this article as: Van Buyten and Höfte: Pythium species from rice roots differ in virulence, host colonization and nutritional profile. $B M C$ Plant Biology 2013 13:203.

\section{Submit your next manuscript to BioMed Central and take full advantage of:}

- Convenient online submission

- Thorough peer review

- No space constraints or color figure charges

- Immediate publication on acceptance

- Inclusion in PubMed, CAS, Scopus and Google Scholar

- Research which is freely available for redistribution 